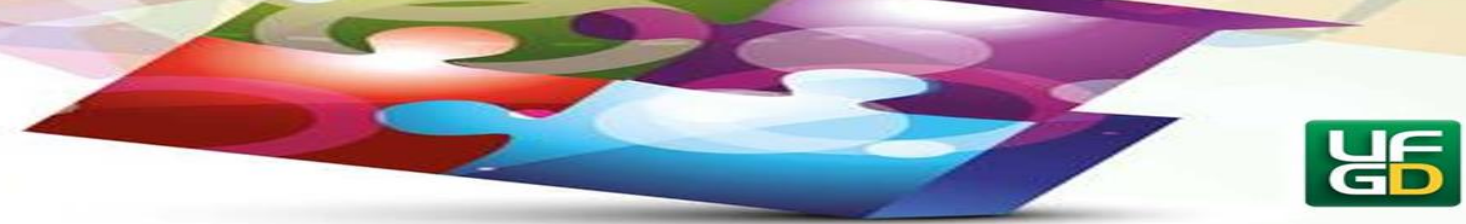

\title{
REFLEXÕES DA FORMAÇÃO INICIAL DE PROFESSORES: O ESTÁGIO SUPERVISIONADO NOS ANOS INICIAIS
}

\section{REFLECTIONS OF INITIAL TEACHER TRAINING: THE STAGE SUPERVISED IN \\ THE INITIAL YEARS}

Simone Aires da SILVA ${ }^{1}$

Rúbia EMMEL ${ }^{2}$

\begin{abstract}
Resumo: este relato apresenta a importância da formação docente para o desenvolvimento profissional de professores que pretendem formar-se competente, qualificado, comprometido e valorizado. Este estudo teve como objetivo compreender e identificar as dúvidas e os desafios no período do estágio supervisionado, fazer uma avaliação da aprendizagem na licenciatura, refletir sobre a construção da identidade docente, aproximar-se do contexto e realidade escolar, articular conhecimentos de disciplinas curriculares e pedagógicas. Tratou-se de uma pesquisa em educação de abordagem qualitativa, uma investigação-ação, na qual foi utilizado para coleta de dados o diário de bordo, com escritas narrativas de memórias de aulas. Percebeu-se a relevância desta investigação-ação que permite ir além do estudo científico, para a formação de um docente pesquisador e reflexivo. Portanto identificou-se que o estágio supervisionado possibilitou experiências docentes considerando o contexto e cotidiano escolar.
\end{abstract}

Palavras-chave: Estágio supervisionado. Formação inicial. Teoria e Prática.

Abstract: this story presents the importance of teacher training for the professional development of teachers who intend to be competent, qualified, committed and valued. This study aimed to understand and identify the doubts and challenges during the supervised internship period, to evaluate the learning in the degree course, to reflect on the construction of the teaching identity, to approach the context and reality of the school, to articulate knowledge of curricular subjects and pedagogical It was a qualitative approach research, an action research, in which the logbook was used for data collection, with written narratives of class memories. The relevance of this research-action that allows to go beyond the scientific study, for the formation of a researcher and reflective teacher, was perceived. Therefore, it was identified that the supervised stage made possible teaching experiences considering the context and daily school.

Keywords: Supervised internship. Initial formation. Theory and Practice.

\footnotetext{
${ }^{1}$ Licenciatura Plena em Pedagogia, Departamento de Educação, Faculdades Três de Maio, Sociedade Educacional Três de Maio (SETREM). E-mail: airessimone@ hotmail.com.

${ }^{2}$ Professora Doutora em Educação nas Ciências, área da Pedagogia, nos Cursos de Licenciatura em Matemática e Licenciatura em Ciências Biológicas. Instituto Federal Farroupilha (IFFAR), Campus Santa Rosa. E-mail: r_emmel@hotmail.com.
} 


\section{Introdução}

O presente relato resulta da intervenção pedagógica realizada durante o $5^{\circ}$ semestre do curso de Licenciatura em Pedagogia, no Estágio Supervisionado II: $1^{\circ}$ ao $5^{\circ}$ ano do Ensino Fundamental, da instituição Faculdades Três de Maio, da Sociedade Educacional Três de Maio (SETREM). O estágio supervisionado nos anos iniciais do Ensino Fundamental possibilitou realizar a prática e conhecer a realidade da sala de aula e do ser docente. Primeiramente foi elaborado um projeto para o desenvolvimento das práticas pedagógicas na escola, o qual teve como tema: "A importância da higiene como um todo e a contribuição do mesmo para uma vida melhor e para saúde". Realizado na turma do $2^{\circ}$ ano " $C$ " do Ensino Fundamental, com 40 h de observação e prática no período vespertino no primeiro semestre de 2016 em uma Escola Municipal do Ensino Fundamental, de Três de Maio-RS.

Tratou-se de uma pesquisa em educação de abordagem qualitativa, uma investigaçãoação (ELLIOT, 1998), na qual foi utilizado para coleta de dados o diário de bordo, no qual realizou-se escritas de narrativas memórias de aulas (PORLÁN; MARTíN, 1997). A produção destas reflexões foram alicerceadas a partir dos embasamentos teóricos: o brincar como um modo de ser e estar no mundo (BRASIL, 2006); Lei de Diretrizes e Bases da Educação Nacional (LDBEN), (BRASIL, 1996); Macedo (2007); Silva (2008); Azzi (1994); Pimenta (2006); Perrenoud (2002); Vygotsky (2007).

O estudo realizado a partir da Lei 12.796 (BRASIL, 2013) de ampliação do ensino fundamental para nove anos, que fez um ajuste alterando a LDBEN (BRASIL, 1996), com a obrigatoriedade da matricula de crianças a partir dos 6 anos no Ensino Fundamental, veio a contribuir com essa etapa da educação e com a permanência da criança na escola.

Conforme os estudos de Ponte et. al (2015), com esta ampliação o governo visa garantir a oportunidade da obrigatoriedade do ensino, sendo que, através desta lei as crianças passam a ingressar o ensino fundamental um ano antes, permanecendo na etapa do Ensino Fundamental dos 6 aos 14 anos. A partir do ingresso das crianças aos 6 anos de idade no Ensino Fundamental, carecemos que se pense nas crianças e nas infâncias, assim indica-se que a alfabetização e o letramento nos anos iniciais ocorram pela ludicidade e pelo brincar. Ponte et. al (2015): "chama a atenção para a concepção de criança enquanto sujeito de direito, possuidora de especificidades próprias da infância e que essas especificidades devem ser trabalhadas dentro e fora da escola" 


\section{HORIZONTES - REVISTA DE EDUCAÇÃO}

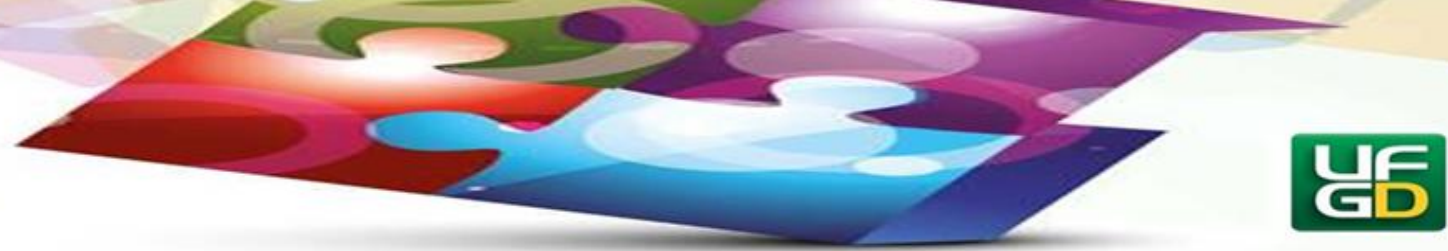

(p. 176). Estas especificidades, foram interpretadas conforme os autores, como o brincar que estava explicito na Educação Infantil e que precisa ser trabalhado no Ensino Fundamental de forma que complemente as ações que estas crianças estariam recebendo, pois "o brincar pode ser um potencializador no processo de aprendizagem, além de contribuir para o desenvolvimento da infância” (PONTE et. al, 2015, p. 176).

A formação inicial de professores nos cursos de licenciaturas torna-se relevante para a formação do profissional e elaboração da identidade docente. Acredita-se que os estudos realizados na durante o estágio supervisionado possibilitaram a reflexão e a articulação da teoria e da prática, como propõe Pimenta e Lucena (2006). Foi possível fazer um contraponto com a prática pedagógica no espaço escolar, na qual enquanto professores foi possível conhecer o trabalho realizado nos anos iniciais e os desafios existentes nesse espaço e os meios adequados para promover uma educação de qualidade. Considerando este contexto o estágio supervisionado é visto como uma via fundamental e essencial para a formação docente, pela pesquisa mais aproxima licenciando da escola, desenvolvendo posturas e habilidades de pesquisador que visam compreender os fatores e aspectos importantes da realidade escolar.

Através das atividades realizadas no estágio foi possível observar o quanto o lúdico contribui para a aprendizagem, por meio das brincadeiras a criança produz significados e entendimentos que a permitem conhecer e compreender o mundo que a cerca, oportuniza a elaboração de hipóteses e através destas podem encontrar respostas para questões do seu cotidiano. Através do referencial vygotskyano compreende-se que o brincar, assume um papel fundamental e significativo na formação da criança e na formação de sua personalidade, desenvolve o cognitivo, o psicológico, o afetivo, a criatividade e a interação no meio social.

\section{Ensino fundamental de nove anos}

Com o intuito de oferecer uma educação de qualidade, reformas são necessárias nas políticas públicas para que ocorram mudanças, com a Lei n ${ }^{\circ} 12.796$ de 4 de abril de 2013, ocorreu um ajuste na redação da LDBEN (BRASIL, 1996) em relação à Emenda Constitucional $\mathrm{n}^{\circ} 59$, de 2009, ampliando o acesso a pré-escola e o ensino fundamental tornando obrigatório o 


\section{HORIZONTES - REVISTA DE EDUCACÃOO}

e-ISSN: 2318-1540

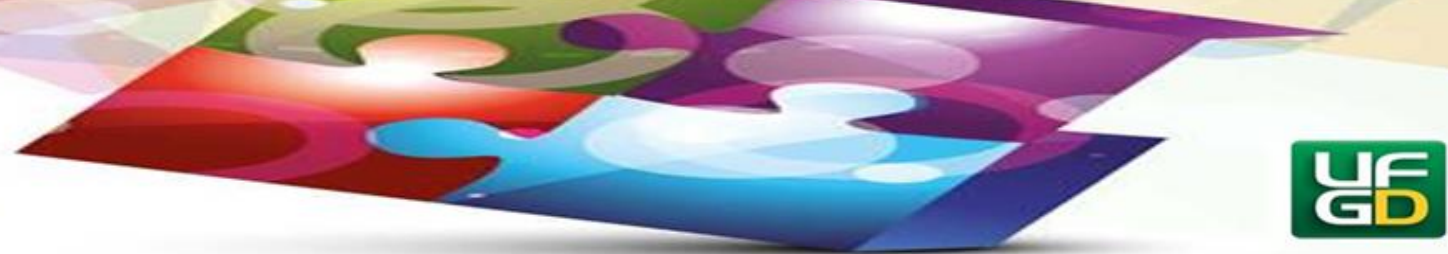

ingresso das crianças na escola a partir dos 4 anos. Acredita-se que a educação obrigatória caracteriza-se para que as crianças das classes populares e filhos/as de trabalhadores tivessem acesso à educação, como acontecia com filhos de pessoas com família privilegia e bem estruturadas, tinham condições financeiras para manter seus filhos em escolas particulares para que tivessem uma educação diferenciada e de qualidade. Considerando a historicidade do caráter elitista da educação, as escolas e os municípios precisaram se organizar para atender estas demandas.

No Artigo 2ª a LDEN (BRASIL, 1996), apresenta os princípios e fins da educação nacional:

Art. $2^{\circ}$. A educação, dever da família e do Estado, inspirada nos princípios de liberdade e nos ideais de solidariedade humana, tem por finalidade o pleno desenvolvimento do educando, seu preparo para o exercício da cidadania e sua qualificação para o trabalho (BRASIL, 1996).

Por força de lei garantiu-se o direito das crianças a educação, de modo que, a família tem o compromisso de matricular as crianças, o estado e o município de oferecer uma educação de qualidade. Conforme a LDBEN (BRASIL, 1996), cabe aos municípios cobrar a matricula, a frequência dessas crianças em idade obrigatória, possibilitar que todas tenham o direito a educação universal e dar subsídio para que as mesmas tenham toda a assistência para manterse na escola, como transporte escolar, alimentação e material didático necessário.

As escolas por sua vez tem se adequado à nova lei e se organizado para que o aluno seja atendido no espaço escolar de acordo com seus direitos. Apesar da obrigatoriedade e a mudança na Emenda Constitucional n ${ }^{\circ}$ 59, de 2009 ampliando a idade para o ingresso a escola e a frequência da criança na escola a partir dos quatro anos de idade. Aos poucos as escolas e as famílias vão se adequando conforme a lei, nos dias atuais algumas crianças ainda encontramse fora da escola ou com um índice baixo de presença, continuando matriculada. Algumas reflexões decorrem do período de estágio supervisionado a respeito do que encontramos na realidade escolar.

\section{Reflexões sobre teoria e prática no estágio supervisionado}




\section{HORIZONTES - REVISTA DE EDUCACÃOO}



A indissociabilidade entre teoria e prática ao longo do Curso de Licenciatura permite ao acadêmico/a fazer várias reflexões, com olhar crítico sobre suas ações e intenções de atuação na sala de aula, possibilitando o olhar, a escuta atenta e sensível, disposto a dialogar e ser coerente, possibilitando que o estágio produzisse novos conhecimentos e significados ao ser professor.

Considera-se relevante que o professor tenha uma observação crítica e atenta, uma escuta sensível e humanizadora, de modo que permita transformar sua prática pedagógica em momentos ímpar de aprendizados, na qual os alunos tornem-se protagonistas, autores sociais de suas produções, com autonomia, preparando-se e dando sentido ao mundo, reconstruindo seu pensar e seu cotidiano.

O estágio supervisionado oportuniza a orientação e a preparação para enfrentar a regência da sala de aula, de como organizar o tempo, o espaço, pensar, elaborar o planejamento e as ações da sua prática. Torna-se relevante refletir a partir da realidade da comunidade escolar, pois, é durante o estágio supervisionado que se poderá entender como funciona e como se organiza a escola, conviver com profissionais do meio e suas realidades. O estágio é o caminho a percorrer para vivenciar as relações entre teoria e prática conforme a realidade e a representação do fazer desta instituição.

Conforme Pimenta e Lucena (2006) em, "O estágio foi identificado como a parte da prática dos cursos de formação de profissionais em geral, em contraposição à teoria",

Não é raro ouvir-se dos alunos que concluem seus cursos se referirem a estes como 'teóricos', que a profissão se aprende 'na prática', que certos professores e disciplinas são por demais 'teóricos'. Que 'na prática a teoria é outra'. No cerne dessa afirmação popular, está a constatação, no caso da formação de professores, de que o curso não fundamenta teoricamente a atuação do futuro profissional nem toma a prática como referência para a fundamentação teórica. Ou seja, carece de teoria e de prática (PIMENTA e LUCENA, 2006, p. 06).

Através das autores (id.) reflete-se que teoria e prática são indissociáveis para uma formação profissional de qualidade, uma precisa da outra para ter significado, aprendizado e entendimento. Mesmo que na teoria à prática seja tão diferente daquela que confrontamos na realidade.

Anseia-se por uma prática pedagógica como estudamos na teoria, mas isso nem sempre ocorre, pois cada escola tem sua proposta pedagógica, sua realidade e seu cotidiano. 


\section{HORIZONTES - REVISTA DE EDUCAÇÃO}

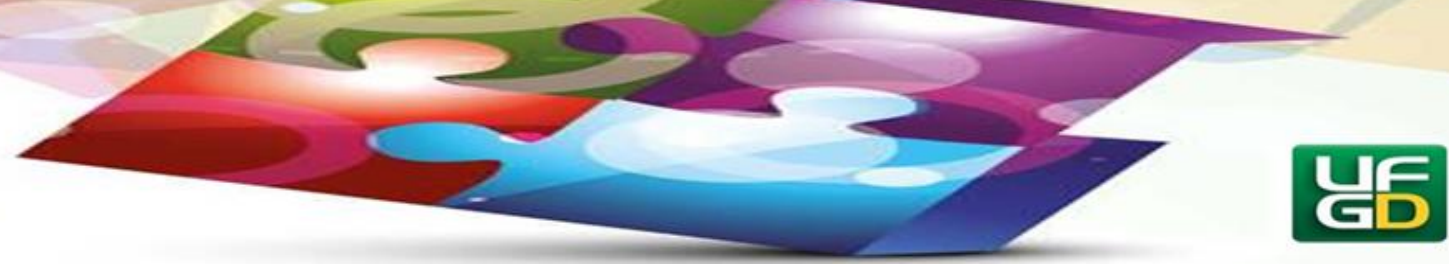

Por mais que o período que se tem para essa intervenção seja considerado curto, é possível criar um breve vínculo com os alunos. É pertinente ressaltar que Azzi (1994) que faz parte do trabalho docente a autonomia didática e a construção do saber pedagógico, que vem ao encontro de uma reflexão sobre os saberes do trabalho desenvolvido pelo professor no qual:

Expressa a síntese de um saber pedagógico possuído pelo professor, saber/es esses adquirido/s, em parte, nos cursos de formação profissional. O saber pedagógico é o saber que o professor constrói no cotidiano de seu trabalho e que fundamenta sua ação docente, ou seja, é o saber que possibilita ao professor interagir com os seus alunos, na sala de aula, no contexto da escola onde atua. A prática docente é, simultaneamente, expressão desse saber pedagógico construído e fonte de seu desenvolvimento (AZZI, 1994, p. 4243).

Nessa perspectiva, a ação pedagógica desenvolvida em sala de aula demonstrará quais aprendizados foram adquiridos e o qual fundamentará a formação desse profissional. Refletir sobre as práticas realizadas no estágio supervisionado sempre é um desafio, lidar com a ansiedade para que tudo ocorra como o planejado, o primeiro contato regendo a turma, a responsável da prática e uma professora experiente observando.

Torna-se necessário pensar se as propostas estão adequadas a realidade, pois, como não é algo que faz parte do cotidiano ou de uma rotina da turma, pode-se reavaliar as atividades planejadas, considerando se estas realmente traduzem aprendizagens mais efetivas.

\section{Analise das práticas realizadas na sala de aula a partir do estágio supervisionado}

Na prática pedagógica é que se desvelam dúvidas, pois se colocam em ação aprendizados construídos, refletem-se sobre os objetivos que espera alcançar com a intervenção, desenvolvem-se habilidades para instrumentalizar as ações na sala de aula. Observa-se como ocorre o desenvolvimento do aluno, como ele se apropria dos ensinamentos, se questiona por encontrar situações problemas, pensa e analisa como agir para resolver. Como lidar com a subjetividade e afetividade do aluno, lidar com situações inesperadas e complexas.

O estágio supervisionado é o momento do fazer reflexivo/ativo, conhecer e enfrentar os desafios da profissão. Conforme aponta Silva (2008), toma-se consciência para que o estágio seja como uma atividade de pesquisa e se aproxime da realidade: 


\section{HORIZONTES - REVISTA DE EDUCAÇÃO}

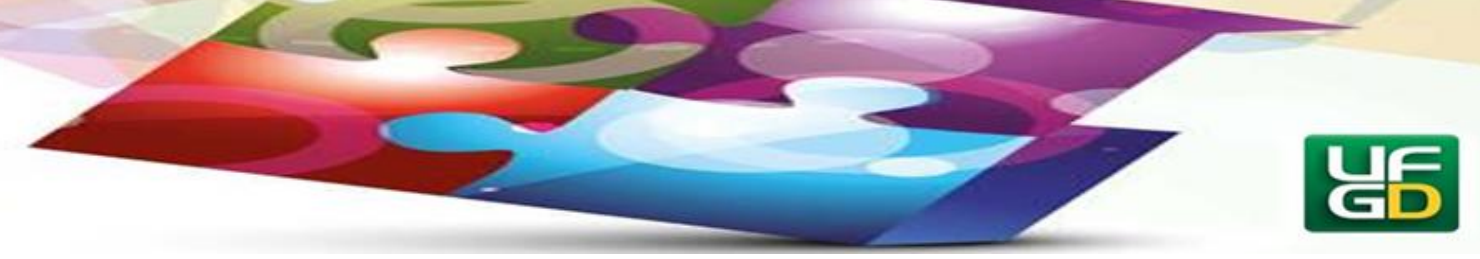

É preciso buscar aprender a realidade e interpretá-la sob diferentes enfoques. Isto requer estudo disciplinado, espírito investigativo de quem não se sente incomodado, desejoso de mudanças. O pensar a mudança já é o primeiro exercício de intervenção. Entretanto, para que a intervenção seja positiva, é preciso ser planejada, exercitada, avaliada. Todas as fases deste processo requerem estudo, busca teórica para compreender cada uma de suas etapas. Neste sentido, o estágio perde o caráter de componente meramente prático, passando a corresponder de fato ao que se propõe a ser: um componente teórico-prático (SILVA, 2008, p. 68).

Durante o estágio supervisionado realizado no $2^{\circ}$ ano de uma turma do primeiro ciclo dos anos iniciais, foi possível intervir através de atividades inovadoras, mudar o cenário e o espaço de aprendizagem. Foi desafiador trabalhar com o lúdico, por vezes, outros professores não compreendem que a ludicidade e a brincadeira podem oportunizar novos conhecimentos para os alunos e não consideram as intencionalidades pedagógicas.

A primeira atividade realizada no estágio supervisionado referente ao tema foi a confecção do corpo humano e suas partes, como na turma o número de meninos e meninas eram quase iguais foi dívida em dois grupos: meninos e meninas, sem desfavorecer os grupos, foi dívida também como seria a participação de cada um na atividade para que todos se envolvessem. O material utilizado foram: papel pardo, tinta guache, linha de lã para o cabelo, EVA picado para formar a vestimenta de ambos. A intenção com essa atividade estava relacionadas as próximas que aconteceriam falando sobre a higiene pessoal (com cada parte do corpo).

Por conseguinte, na atividade posterior para a contação de história foi utilizado: O livro da Saúde (ANGELIN, 2008), fantoches, uma TV confeccionada com caixa de papelão, produtos de higiene pessoal (matérias sem uso como: sabonete, xampu, esponja para banho, escova para unhas, escova de dente, pasta de dente, entre outros), para a contação de história.

Decorrente a contação de história os alunos puderam manusear todo material utilizado, foi um momento de interação, socialização, aprendizado, questionamentos sobre a higiene pessoal, de como é essa prática em casa e em outros espaços. Dessa forma, ao ouvir histórias "que se pode sentir várias emoções, como a tristeza, a raiva, o medo [...], e viver profundamente tudo o que as narrativas provocam em quem as ouve [...] Pois é ouvir, sentir e enxergar com os olhos do imaginário" (ABRAMOVICH, 1997, p. 17). Através das histórias as crianças passam a entender o mundo, tudo a sua volta, estabelecendo relações, interações e socialização com o outro. 


\section{HORIZONTES - REVISTA DE EDUCAÇÃO}

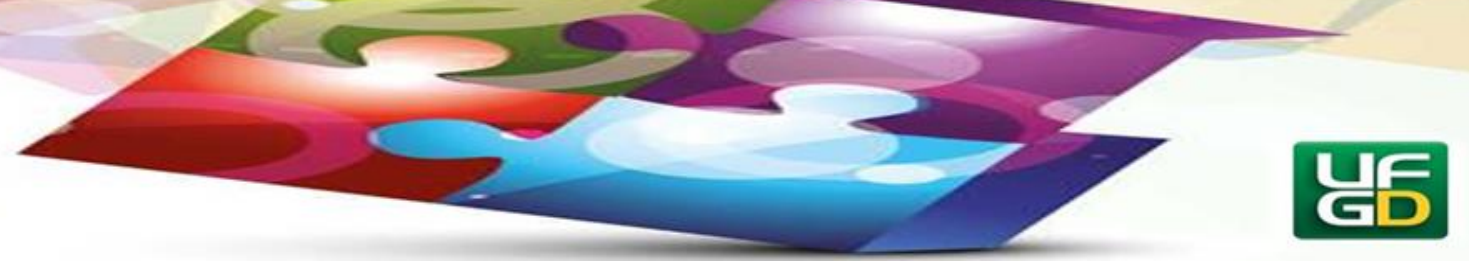

A saúde bucal foi outra atividade significativa, para realizá-la foi convidada uma enfermeira no Posto de Saúde do bairro onde localiza-se a escola, kits para cada aluno fazer a higiene bucal. Depois da atividade puderam levar para casa e colocar em prática o que aprenderam na escola. Para isso, foi assistido o vídeo sobre Saúde Bucal, no decorrer foi distribuído para cada aluno o kit e nos dirigimos para a área aberta com pias no pátio da escola e colocar em prática o que foi visto no vídeo.

A escovação foi um momento de descontração e diversão, mesmo nesse momento que parecia uma brincadeira, os alunos tiveram o entendimento de como é importante cuidar não só da limpeza dos dentes, chamou-se a atenção para a saúde e a higiene com toda a boca, ou seja, dentes gengivas e língua. A forma correta de fazer a escovação as causas da falta de cuidado com a higiene da boca, entre outras informações.

Nessa perspectiva, percebeu-se durante as observações que alguns professores ainda desenvolvem atividades com base em uma educação tecnicista e conteudista em suas práticas pedagógicas. Através de Macedo (2008) compreende-se que o brincar é algo sério para a criança, uma vez que para isso ela precisa desenvolver atenção e concentração, foco, direção e disponibilidade. A partir destas afirmações foi possível compreender que mais importante na vida da criança é o espaço, tempo, as relações estabelecidas com as pessoas: "seu conhecimento, seu corpo, seus conhecimentos, suas relações com as pessoas, objetos e atividades- são oferecidas a uma situação na qual ela, quase sempre, é a única protagonista, a responsável pelas ações e fantasias" (MACEDO, 2008, p. 14).

Procurou-se outro caminho para a prática, onde foi permitido brincar e aprender, participar, ser agente da construção. Trabalhando com a imaginação e o faz de conta foi montado um mercado na sala com embalagens de produtos de limpeza em geral, tanto pessoal, como para o ambiente onde vivemos. Nesta atividade foi enviado para casa um bilhete explicando sobre a atividade proposta as crianças e seria necessário que cada aluno trouxesse de casa embalagens (sucata) de produtos de limpeza em geral, higienizados para montarmos um mercado na sala.

A partir das embalagens que foram trazidas por eles de casa, montou-se um mercado, em que todos puderam participar, sendo vendedores ou consumidores, com dinheiro de papel, as crianças compravam o produto, assim estabeleceu-se o diálogo entre as crianças e com a professora estagiária, as crianças questionavam para que serviam os produtos de higiene. 


\section{HORIZONTES - REVISTA DE EDUCAÇÃO}

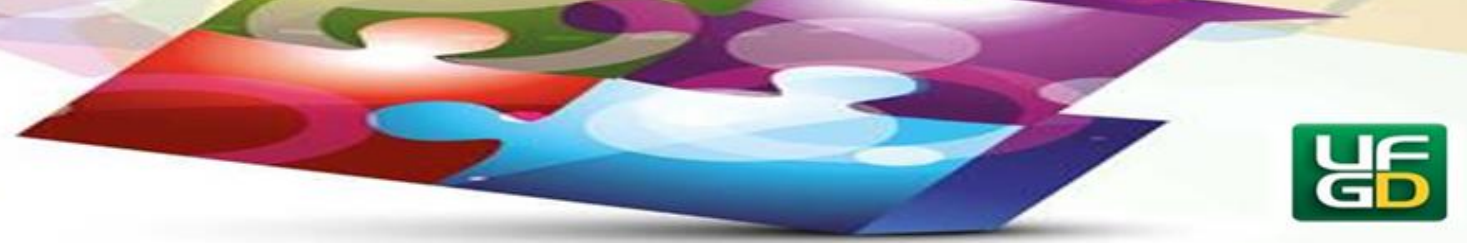

Foi possível perceber que nas dinâmicas envoltas no faz de conta as crianças foram aprendendo sobre cada produto, trocando informações, e seguiam questionando: como se utilizava em casa? Qual o cálculo para saber o custo/valor de cada produto? Assim sentiam a necessidade de ler os rótulos dos produtos e verificavam informações envolvendo as grandezas e as medidas, as origens e meios de produção dos produtos, o local em que foi fabricado ou embalado, alguns pediram para procurar no mapa algumas cidades e perceberam que há produtos que vem de fábricas que ficam muito distantes do local em que moram.

Compreendeu-se que as atividades realizadas utilizando o lúdico, contribuíram com a construção da aprendizagem de modo divertido, criativo, possibilitando a utilização de materiais concretos e promovendo a vivência, a manipulação e exploração de meios e objetos. Permitindo que as crianças através do lúdico elaborem hipóteses e conceitos de determinados assuntos, conforme as Diretrizes Curriculares Nacionais da Educação Básica:

As crianças precisam brincar em pátios, quintais, praças, bosques, jardins, praias, e viver experiências de semear, plantar e colher os frutos da terra, permitindo a construção de uma relação de identidade, reverência e respeito para com a natureza. Elas necessitam também ter acesso a espaços culturais diversificados: inserção em práticas culturais da comunidade, participação em apresentações musicais, teatrais, fotográficas e plásticas, visitas a bibliotecas, brinquedotecas, museus, monumentos, equipamentos públicos, parques, jardins (BRASIL, 2013, p. 94).

O brincar é parte importante da educação inovadora e contemporânea, e ao mesmo tempo pode possibilitar o conhecimento e a construção da cultura dos sujeitos inseridos naquele espaço. Para além desta atividade o projeto envolveu a contação de história (livros de literatura infantil) e vídeos de como fazer uma higiene e levar uma vida saudável. Vygotsky (2007) aponta que a "ação numa situação imaginária ensina a criança a dirigir seu comportamento não somente pela percepção imediata dos objetos ou pela situação que lhe afeta de imediato, mas também pelo significado da situação" (VYGOTSKY, 2007, p. 114).

Sobre a higiene também foi abordado o tema da conscientização da limpeza e coleta de lixo. Em uma aula fizemos um passeio no pátio da escola e na vizinhança, observando a condição de limpeza e como eram depositados os lixos, foi recolhido um pouco do lixo encontrado em local incorreto pelas crianças e depositados no lugar certo. Nesta atividade considerou-se a importância de desenvolver momentos vinculados a uma situação real: "a promoção de atividades que favoreçam o envolvimento da criança em brincadeiras, 


\section{HORIZONTES - REVISTA DE EDUCAÇÃO}

e-ISSN: 2318-1540

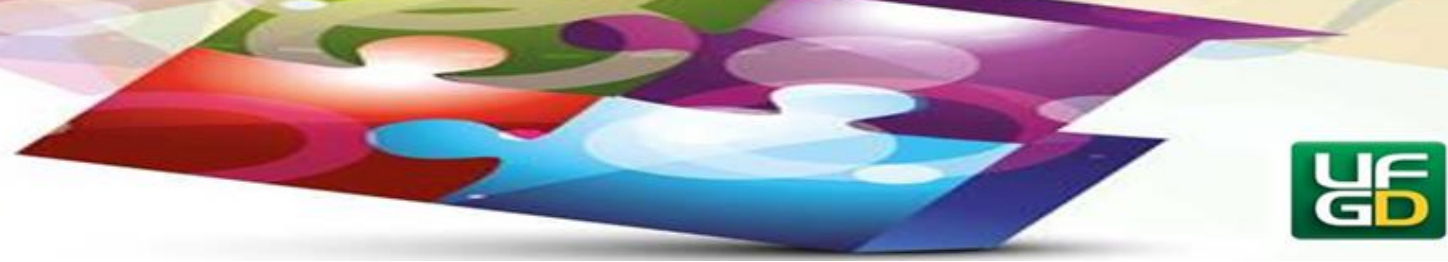

principalmente aquelas que promovem criação de situações imaginárias, tem nítida função pedagógica" (OLIVEIRA, 2010, p. 69).

Tivemos uma aula em que foram realizadas leituras de folders e panfletos explicativos doados pela Secretaria Municipal de Saúde apresentando a forma inadequada e adequada de cuidar do espaço onde vivemos, das doenças que se manifestavam na falta de limpeza de pátios e terrenos, na forma inadequada de recolher e depositar o lixo para coleta. Para Macedo et al. (2007, p. 19), “algo só é obstáculo para alguém se implicar alguma dificuldade, maior ou menor, que requeira superação". Com isso, será preciso "prestar mais atenção, repetir, pensar mais vezes ou mais profundamente, encontrar ou criar alternativas" (MACEDO et. al, 2007, p. 19). O lúdico é desafiador, surpreende, provoca o pensamento, alternativas, hipóteses, não controla resultados, recriasse em outros espaços.

\section{Considerações finais}

A intervenção possibilitou perceber a importância da reflexão sobre o estágio e relação indissociável da teoria com a prática, muitas vezes estas relações não são consideradas para representar a realidade vivenciada nas salas de aula.

Portanto, é significativo que cada vez mais se realize uma prática educativa de qualidade e professores com formações adequadas, que saibam lidar da melhor maneira com os desafios do espaço escolar e, que compreendam seus alunos. Proponham uma prática pensada nos alunos e em seu cotidiano, que possam atender em cada espaço pensando em suas dificuldades e especificidades, que sejam mediadas através do diálogo, da interação social, de processos de ensino e de aprendizagem intencionais.

Destaca-se com este estudo a necessidade de pensar na importância do desenvolvimento e da identidade profissional dos professores, o estágio supervisionado é o momento de pensar sobre os saberes adquiridos no curso de Licenciatura. A relação entre a teoria e a prática no estágio supervisionado oportunizou inúmeras reflexões.

Em vista dos argumentos apresentados compreende-se, que por meio da reflexão, ação e a prática promove a interação entre professor, aluno e profissional em geral do espaço escolar. Destaca-se a importância do licenciando se inteirar de como é organizado esse espaço, 


\section{HORIZONTES - REVISTA DE EDUCAÇÃO}

e-ISSN: 2318-1540

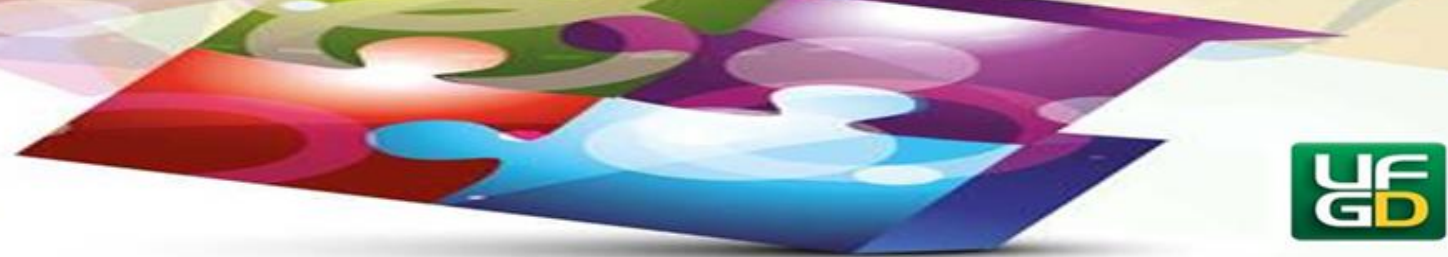

reconhecer quais os métodos de ensino, didáticas e práticas que vão ser exploradas durante o estágio.

Por fim, acredita-se que através das intervenções realizadas no período do estágio supervisionado a ludicidade, ou seja, o brincar/brincadeiras/jogos fez-se necessária ao desenvolvimento e a aprendizagem das crianças. Portanto, a brincadeira pode ser vivenciada, não apenas como diversão, mas com objetivo de desenvolver as habilidades e potencialidades da criança, considerando as intencionalidades pedagógicas. De tal forma que o conhecimento seja construído pelas e/ou entre as relações interpessoais e trocas que se estabelecem durante toda a formação da criança.

\section{Referências}

ABRAMOVICH, Fanny. Literatura infantil: gostosuras e bobices. São Paulo: Scipione, 1997.

ANGELINI, Paulo Ricardo. O livro a saúde. Erechim: Ed Elbra. 10v. 2008.

AZZI, Sandra. Trabalho docente: autonomia didática e construção do saber pedagógico. In: PIMENTA, Selma. G. (Org.). Saberes pedagógicos e atividade docente. São Paulo: Cortez, 2002.

BRASIL. Ministério da Educação. Diretrizes Curriculares Nacionais para a Educação Básica, 2013. Disponível em: http://portal.mec.gov.br/docman/julho-2013-pdf/13677diretrizes-educacao-basica-2013-pdf/file. Acesso em: 13/06/2018.

BRASIL. Lei $n$. 12.796, de 4 de abril de 2013. Altera a Lei no 9.394, de 20 de dezembro de 1996, que estabelece as diretrizes e bases da educação nacional, para dispor sobre a formação dos profissionais da educação e dar outras providências. Disponível em: http://www.planalto.gov.br/ccivil_03/_ato2011-2014/2013/lei/112796. htm. Acesso em: 13/06/2018.

BRASILMinistério da Educação. Lei de Diretrizes e Bases da Educação Nacional. Disponível em: http://www.planalto.gov.br/ccivil_03/LEIS/19394.htm. Acesso em: 13/06/2016.

BRASIL. Ministério da Educação. O brincar como um modo de ser e estar no mundo. In: BEAUCHAMP, J.; PAGEL, S. D.; NASCIMENTO, A. R. (Orgs). Ensino fundamental de nove anos: orientações para a inclusão da criança de seis anos de idade. Brasília: Ministério da Educação, Secretaria de Educação Básica, 2007. 135 p. Disponível em: http://portal.mec.gov.br/seb/arquivos/pdf/Ensfund/ ensifund9 ano basefinal.pdf. Acesso em 10/06/2016. 


\section{HORIZONTES - REVISTA DE EDUCAÇÃO}

e-ISSN: 2318-1540

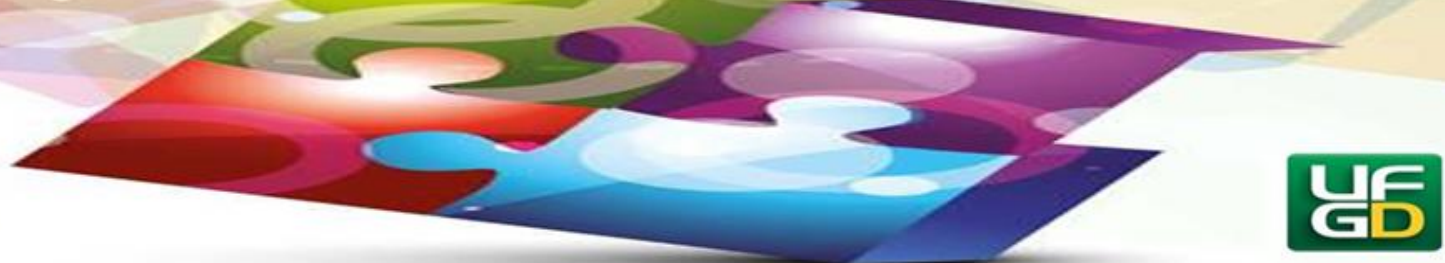

ELLIOTT, J. Recolocando a pesquisa-ação em seu lugar original e próprio. In: GERALDI, C. M. G.; FIORENTINI, D.; PEREIRA, E. M. A. (Orgs.). Cartografias do trabalho docente: professor(a) pesquisador(a). Campinas: Mercado das Letras, 1998.

MACEDO, L. et. al. Os Jogos e o Lúdico na Aprendizagem Escolar. -Dados eletrônicosPorto Alegre: Artmed, 2007.

SILVA, L. C.; MIRANDA, Maria I. (orgs.). Estágio Supervisionado e prática de ensino: desafios e possibilidades. Araraquara, SP: Junqueira \& Marin: Belo Horizonte, MG:

FAPEMIG, 2008.

OLIVEIRA, M. K. de. Vygotsky: aprendizado e desenvolvimento um processo sóciohistórico. 4. ed. São Paulo: Scipione, 1997.

PIMENTA, Selma G, LUCENA, Maria S. Estágio e docência: diferentes concepções. Revista Poíses Pedagógica. Catalão, v. 3, n. 3 e 4, p. 5-24, 2006.

PONTE. Adriana Eugênio de Souza; et al. A Distância Adulto/Criança e seus Reflexos no Processo Educacional. in: SODRÉ, Liana Gonçalves Pontes. Crianças, Infâncias e Educação Infantil. Curitiba: Editora CRV, 2015.

PORLÁN, R.; MARTÍN, J. El diario del professor: um recurso para investigación em el aula. Diáda: Sevilla, 1997.

VYGOTSKY, L. S. A formação social da mente. 7 ed. São Paulo: Martins Fontes, 2007.

Enviado : 16/06/2018.

Aceito : 19/12/2018. 